\title{
Toxicity and Synergism of Insecticides Against Susceptible and Pyrethroid-Resistant Third Instars of the Tobacco Budworm (Lepidoptera: Noctuidae)
}

\author{
C. CAMPANHOLA' AND F. W. PLAPP, JR.
}

Department of Entomology, Texas A \& University, College Station, Texas 77843

\begin{abstract}
1. Econ Entomol, 82(6): 1495-1501 (1988)
ABSTRACT Third-instar tobacco budworms, Heliothis virescens (F.), susceptible or resistant to pyrethroids were tested by exposure to residues of insecticides in glass liquid scintillation vials. These bioassays were done to find alternative insecticides or insecticide combinations for control of larvae resistant to pyrethroids. to evaluate the effect of synergists on insecticide toxicity and resistance, and to establish the main mechanisms of resistance present. Insecticides effective for control of resistant third-instar tobacco budworms included profenofos, sulprofos, acephate, endosulfan, methomyl, and thiodicarb. Cypermethrin combined with chlordimeform, piperonyl butoxide, or both was highly effective against resistant larvae. With other insecticides, neither piperonyl butoxide nor chlordimeform produced more than five-fold synergism. The only synergistic insecticide combination against resistant larvae was cypermethrin plus methyl parathion. Thus, use of other combinations had no advantage compared with use of alternative insecticides. High-level cypermethrin resistance, resistance to methyl parathion, and synergism of these insecticides by piperonyl butoxide provide evidence for metabolic resistance in this life stage. Therefore, we conclude that metabolic resistance seems to be the rnost important resistance mechanism in large tobacco budworms.
\end{abstract}

KEY WORDS Insecta, Heliothis, pyrethroids, resistance, control

RESISTANCE OF THE TOBACCO BUDWORM, Heliothis virescens $(F)$, to pyrethroid insecticides is widely present in the five state area of Arkansas, Oklahoma, Texas, Louisiana, and Mississippi (Plapp et al. 1988). Monitoring studies in Texas showed that the problem of pyrethroid resistance was less serious in 1987 and 1988 than in 1986, a result that may be related to the implementation of strategies adopted for resistance management (Anonymous 1986; Frisbie \& Plapp 1987; Plapp et al., 1987. 1988 , in press).

Occurrence of pyrethroid resistance in the tobacco budworm has raised great interest in the search for strategies to prevent or overcome resistance in the field (Luttrell \& Roush 1987, Campanhola \& Plapp 1988). Neonate larvae are usually the target life stage for control early in the season (Campanhola \& Plapp 1989a,b). Control of larger larvae is more important as the season progresses and generations overlap. Large larvae are harder to control compared with earlier stages, probably because of their inherently greater capability to metabolize xenobiotics and insecticides (Muehleisen 1987). Because of this, selection for metabolic resistance to insecticides in late instars may be easier.

\footnotetext{
Turrent addres: EMBRAPA/CNPDA, Caixa Postal 69,13820 Jaguariúna, SP, Brazil
}

Pyrethroid resistance in the tobacco budworm bas been measured in many studies with third instars, the stage usually tested in the laboratory. Progeny of field-collected tobacco budworms in the Imperial Valley, California, showed a steady increase in resistance from 1979 to 1981 (MartinezCarrillo \& Reynolds 1983). Resistance levels to permethrin and fenvalerate increased to 51 -fold and 29-fold, respectively, at the end of that period. In Texas, a 21 -fold difference in $\mathrm{LD}_{50}$ 's of fenvalerate was observed between laboratory and field strains (Harding et al. 1977). Plapp (1981) tested thirdand fourth-instar tobacco budworms collected from cotton fields in Texas and observed about 6- and 2-fold resistance to permethrin and fenvalerate, respectively. In a 5-yr study with third instars, Staetz (1985) found that tobacco budworm populations in the southwest (Texas, Arizona, and California) were generally less susceptible to permethrin than those in the southeast (Alabama and Georgia). Tests showed that $F$, third instars of field strains collected in Louisiana, Texas, Arizona, and Mississippi during 1985 and 1986 showed moderate to high levels of resistance to fenvalerate (2-35-fold), permethrin (1-74-fold), and cypermethrin (2-9-fold) (Leonard et al. 1987).

In a previous study (Campanhola \& Plapp 1989b), we found that resistance in neonate tobacco budworms extended to all pyrethroids tested. How- 
Table 1. Toxicity of insecticides with and without chlordineform (CDF) and piperonyl butoxide (PB) to susceptible (S) and resistant ( $\mathbb{f}$ ) third-instar tobaceo budworms

\begin{tabular}{|c|c|c|c|c|c|c|}
\hline \multirow{2}{*}{ Insecticide + synergists } & \multicolumn{3}{|c|}{ Stoneville (S) } & \multicolumn{3}{|c|}{$[\mathrm{CI}(\mathrm{R})$} \\
\hline & $n^{a}$ & Slope $( \pm$ SD) & $L C_{50}(95 \% \mathrm{CL})^{b}$ & $n^{a}$ & Slope $( \pm S D)$ & $\mathrm{LC}_{50}(95 \% \mathrm{CL})^{b}$ \\
\hline Cypermethrin & 145 & $2.02( \pm 0.32)$ & $1.29(0.92-1.71)$ & 125 & $0.78( \pm 0.25)$ & $1,287.46(594.3-3,325)$ \\
\hline Cypermethrin + CDF & 117 & $1.33( \pm 0.29)$ & $0.25(0.16-0.41)$ & 100 & $1.6)( \pm 0.39)$ & $16.74 \quad(8.23-24.82)$ \\
\hline Cypernethrin + PB & 128 & $2.34( \pm 0.42)$ & $0.53(0.41-0.74)$ & 120 & $2.14( \pm 0.35)$ & $8.10 \quad(5.96-10.84)$ \\
\hline Cypermethrin + CDF + PB & 75 & $3.21( \pm 0.66)$ & $0.27 \quad(0.21-0.35)$ & 108 & $1.68( \pm 0.34)$ & $4.98 \quad(3.46-7.60)$ \\
\hline Methyl parathion & 149 & $1.69( \pm 0.28)$ & $12.57(8.57-17.15)$ & 174 & $1.62( \pm 0.23)$ & $237.79(171.6-321.6)$ \\
\hline Metbyl paratbion + CDF & 95 & $2.20( \pm 0.45)$ & $3.74 \quad(2.70-5.12)$ & 106 & $2.97( \pm 0.48)$ & $2.91 \quad(2.25-3.66)$ \\
\hline Methyl parathion + $\mathrm{PB}$ & 177 & $0.72( \pm 0.19)$ & $32.90(17.91-91.10)$ & 137 & $1.13( \pm 0.26)$ & $48.23(28.58-78.56)$ \\
\hline Methyl parathion $+\mathrm{CDF}+\mathrm{PB}$ & - & - & - & 75 & $2.45( \pm 0.66)$ & $3.77(2.38-5.05)$ \\
\hline Chiorpyrifos & 78 & $2.87( \pm 0.73)$ & $3.57 \quad(2.77-5.59)$ & 100 & $3.51( \pm 0.57)$ & $10.19(8.21-12.93)$ \\
\hline Chlorpyritos + CDF & 141 & $2.20\langle \pm 0.37\rangle$ & $3.57 \quad(2.77-4.60)$ & 99 & $2.65( \pm 0.58)$ & $5.31 \quad(4.15-6.95)$ \\
\hline Chlorpyrifos + PB & 67 & $2.80( \pm 0.63)$ & $18.83\langle 13.10-25.05\rangle$ & - & - & - \\
\hline Profenofos & 73 & $3.33( \pm 0.66)$ & $1.23 \quad(0.97-1.62)$ & 105 & $2.73( \pm 0.49)$ & $1.16(0.88-1.47)$ \\
\hline Profenofos + CDF & 70 & $3.45( \pm 0.75)$ & $0.92 \quad(0.71-1.19\}$ & 100 & $3.87( \pm 0.59)$ & $1.38(1.11-1.71)$ \\
\hline Profenofos $+\mathrm{PB}$ & - & $+\infty$ & - & 70 & $1.89( \pm 0.58)$ & $2.67 \quad(1.79-4.82)$ \\
\hline Sulprofos & 93 & $2.76( \pm 0.48)$ & $1.15(0.85-1.50)$ & 127 & $2.56( \pm 0.44)$ & $1.76(1.26-2.24)$ \\
\hline Sulprofos + CDF & 229 & $2.75( \pm 0.32)$ & $1.09 \quad(0.92-1.28)$ & 63 & $2.64( \pm 0.67)$ & $1.66(1.08-2.26)$ \\
\hline Sulprofos + PB & - & - & - & 90 & $2.65( \pm 0.50)$ & $4.46(9.40-6.14)$ \\
\hline Acephate & 84 & $1.68( \pm 0.44)$ & $17.25(10.94-27.09)$ & 106 & $1.85( \pm 0.38)$ & $25.60(18.39-41.42\rangle$ \\
\hline Acephate + CDF & 75 & $3.81( \pm 0.77)$ & $4.01 \quad(3.13-4.93)$ & 83 & $5.55( \pm 0.96)$ & $5.82(4.96-6.92)$ \\
\hline Acephate + PB & 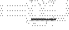 & $=$ & - & 75 & $2.41( \pm 0.58)$ & $22.08(15.56-30.40)$ \\
\hline Acephate $+\mathrm{CDF}+\mathrm{PB}$ & $=$ & $=4$ & - & 77 & $3.08( \pm 0.61)$ & $5.57(4.15-7.32)$ \\
\hline Methomyl & 177 & $2.85( \pm 0.39)$ & $0.22 \quad(0.19-0.27)$ & 109 & $1.45\langle \pm 0.35\rangle$ & $0.95(0.63-1.60)$ \\
\hline Methomyl + CDF & 75 & $4.57( \pm 0.83)$ & $0.23(0.19-0.28\rangle$ & 110 & $1.69( \pm 0.34)$ & $0.29(0.18-0.41)$ \\
\hline Methomyl + PB & - & - & - & 130 & $1.35( \pm 0.36)$ & $0.46 \quad(0.23-0.67)$ \\
\hline Methonyl + CDF + PB & - & - & - & 98 & $1.85( \pm 0.42)$ & $0.53(0.35-0.75)$ \\
\hline Thiodicarb & 95 & $2.14( \pm 0.44)$ & $2.94 \quad(2.05-4.01)$ & 148 & $1.28( \pm 0.51)$ & $11.38 \quad(7.44-17.18)$ \\
\hline Thiodicarb + CDF & 70 & $1.69( \pm 0.60)$ & $0.61 \quad(0.15-0.94)$ & 75 & $2.95( \pm 0.61)$ & $1.95(1.42-2.52)$ \\
\hline Thiodicarb + PB & - & - & - & 107 & $0.89( \pm 0.34)$ & $7.53(2.75-18.90)$ \\
\hline Thiodicarb + CDF + PB & - & - & - & 93 & $1.71( \pm 0.40)$ & $1.84(1.24-2.84)$ \\
\hline Endosulfan & 78 & $3.10( \pm 0.69)$ & $4.61 \quad(3.51-5.87)$ & 100 & $2.14( \pm 0.42)$ & $6.56 \quad\{4.75-8.97\}$ \\
\hline Endosulfan + CDF & 74 & $2.98( \pm 0.65)$ & $0.87(0.65-1.14)$ & 125 & $2.06( \pm 0.32)$ & $2.23(1.64-2.99)$ \\
\hline
\end{tabular}

"Number of larvae tested excluding controls.

${ }^{h}$ Concentrations are expressed in micrograns of insecticide per vial.

ever, we observed no resistance to other classes of insecticides. Target site resistance to pyrethroids appeared to be the main resistance mechanism expressed in this life stage. Resistance in adults was similar to that in neonates.

In this study, we report results of bioassays of third-instar tobacco budworms susceptible and resistant to pyrethroids. We tested insecticides of different classes, with and without synergists. Tests with this stage permit comparisons with other studies of resistance in the tobacco budworm. The purposes of our tests were to find alternative insecticides or insecticide combinations for controlling pyrethroid-resistant large larvae, to evaluate the effect of insecticide synergists on insecticide toxicity and resistance, and to establish the main resistance mechanisms present.

\section{Materials and Methods}

Insects and Insecticides. The tobacco budworm strains used and rearing procedures were the same as previously described (Campanhola \& Plapp 1989b). Test insecticides and sources were also listed previously (Campanhola \& Plapp 1989b).

Bioassays. Test insects were individually reared to the third instar in plastic vials $(1.7 \mathrm{~cm}$ diameter by $6.3 \mathrm{~cm}$ long) on artificial diet for $6-8 \mathrm{~d}$ before testing. The vial technique (Plapp 1979) was used to expose larvae to insecticides. To avoid cannibalism, one larva was placed in each vial along with approximately $1 \mathrm{~g}$ of artificial diet. All insecticides were tested with susceptible and resistant strains, except for some combinations that were tested only with the resistant strain. All tests with resistant larvae were done on the $F_{1}-F_{4}$ generations of the strain as received from ICI Americas, Goldsboro, N.C. Insecticides plus chlordimeforoo or piperonyl butoxide were tested at a $1: 10$ (wt/wt) ratio, All insecticides were tested with chlordimeform, but only some were tested with piperonyl butoxide. Some insecticides were tested with both synergists at a 1:10:10 (insecticide/chlordimeform/piperonyl butoxide) ratio. Larvae were exposed to three to live concentrations of insecticides. At least 20 larvae were tested per insecticide concentration with a minimum of four replicates of Give larvae each. Responses were measured after 72 h exposure. The criterion for death was the lack of larval growth or inability to walk and stand, or both. During rearing and bioassays the insects were maintained in an incubator at $25 \pm 1{ }^{\circ} \mathrm{C}$ and a photoperiod of 14:10 (L:D). When we began the bioassays, the resistance level to cypermethrin in ICI larvae was about $1,000-$ fold. At the end of testing, after four generations without selection with 
Table 2. Toxicity of insecticide combinations with and withont chlordimeform (CDF) and piperonyl butoxide (PB) to susceptible (5) and resistant (R) third-instar tobaceo budworms

\begin{tabular}{|c|c|c|c|c|c|c|}
\hline \multirow{2}{*}{ Insecticide + synergists } & \multicolumn{3}{|c|}{ Staneville (S) } & \multicolumn{3}{|c|}{$1 \mathrm{CI}(\mathrm{R})$} \\
\hline & $n^{a}$ & Slope $( \pm S D)$ & $\mathrm{LC}_{50}(95 \% \mathrm{CL})^{b}$ & $n^{a}$ & Slope $( \pm S D)$ & $\mathrm{LC}_{50}(95 \% \mathrm{CL})^{b}$ \\
\hline Chlorpyrifos + sulprofos & 104 & $3.59( \pm 0.61)$ & $0.59(0.49-0.74)$ & 59 & $4.87( \pm 1.10)$ & $1.06(0.86-1.33)$ \\
\hline Cypermethrin + thiodicarb & 111 & $1.95( \pm 0.39)$ & $0.46(0.34-0.67)$ & 119 & $1.29( \pm 0.30)$ & $5.58(2.68-8.64)$ \\
\hline Cypermethrin + thiodicarb + CDF & 123 & $1.75( \pm 0.36)$ & $0.25(0.17-0.35)$ & 79 & $1.84( \pm 0.53)$ & $2.07(1.23-3.07)$ \\
\hline Cypermethrin + methyl parathion & - & - & - & 126 & $1.94( \pm 0.39)$ & $4.88(3.67-7.19)$ \\
\hline Cypermethrin + methyl parathion + CDF & - & - & - & 87 & $2.64( \pm 0.51)$ & $2.99(2.24-3.97)$ \\
\hline Cypermethrin + methyl parathion + $\mathrm{PB}$ & - & - & - & 98 & $1.89( \pm 0.35)$ & $7.21(5.05-10.97)$ \\
\hline Cypennethrin + sulprofos & - & $\ldots$ & - & 102 & $1.94( \pm 0.43)$ & $2.45(1.65-3.38)$ \\
\hline
\end{tabular}

- Number of larvae tested excluding controls.

"Concentrations are expressed in micrograms of eatch insecticide per vial.

insecticides, the resistance level to cypermethrin was about 100 -fold. The dose-response data represent the average of tests done during four dif. ferent generations, usually one test per generation.

Data Analyses. Data from all bioassays were corrected for control mortality using Abbott's (1925) formula. Thereafter, $\mathrm{LC}_{50} \mathrm{~s}$ in $\mu \mathrm{g}$ toxicant per vial and slopes of response curves were estimated by probit analysis (SAS Institute 1982). Resistance levels were determined by dividing the $\mathrm{LC}_{50}$ of each toxicant for the resistant strain by the $L_{30}$ for the susceptible strain. Synergism levels due to chlordimeform and piperonyl butoxide were calculated by dividing the $L_{50}$ for the insecticide only by the $\mathrm{LC}_{s 0}$ for the insecticide plus synergist(s). The synergistic effect of insecticide combinations was evalwated by cotoxicity coefficients (Sun \& Johnson 1960).

\section{Results and Diseussion}

Toxicity data for insecticides only and insecticides in combination with chlordimeform or piperonyl butoxide revealed a wide range of responses within and between strains (Table 1). For susceptible larvae, methomyl was the most toxic insecticide tested $\left(\mathrm{LC}_{50}=0.22 \mu \mathrm{g}\right.$ per vial), followed by sulprofos and profenofos $\left(\mathrm{LC}_{30}=1.15\right.$ and $1.23 \mu \mathrm{g}$ per vial, respectively). Cblordimeform was only weakly synergistic with profenofos, sulprofos, and chlorpyrifos, but increased toxicity of the other insecticides tested by several fold. Piperonyl butoxide was synergistic with cypermethrin, but antagonistic with methyl parathion and chlorpyrifos, the only other insecticides with which it was tested.

For resistant larvae, methomyl was again the most toxic insecticide tested $\left(\mathrm{LC}_{5 a}=0.95 \mu \mathrm{g}\right.$ per vial), followed by profenofos and sulprofos ( $\mathrm{LC}_{50}$ $=1.16$ and $1.76 \mu \mathrm{g}$ per vial, respectively). Cypermethrin and methyl parathion were least toxic to resistant larvae, indicating a high level of resistance to these insecticides. Chlordimeform was strongly synergistic with cypermethrin and methyl parathion. Piperonyl butoxide was more effective than chlordineform as a synergist for cypermethrin, but less effective with methyl parathion. As with sus- ceptible larvae, chlordimeform was not synergistic with profenofos and sulprofos, but was synergistic with chlorpyrifos, acephate, methomyl, thiodicarb, and endosulfan. Piperonyl butoxide was not synergistic with the other organophosphates and was less effective than chlordimeform in combination with methomyl and thiodicarb.

The toxicity of combinations of cypermethrin with other insecticides to third instars is shown in Table 2. The most toxic combination was cypermethrin plus sulprofos with an $\mathrm{LC}_{50}$ of $2.45 \mu \mathrm{g}$ of each insecticide per vial. However, the combination of chlorpyrifos with sulprofos was more toxic than any of the cypermethrin combinations $\left(\mathrm{LC}_{50}\right.$ value of $1.06 \mu \mathrm{g}$ of each insecticide per vial, Table 2). The cotoxicity coefficients for the insecticide combinations for $\mathrm{YCl}$ third instars were quite variable. They were $41.2,2.0,0.7$, and 1.4 for cypermethrin plus methyl parathion, cypermethrin plus thiodicarb, cypermethrin plus sulprofos, and chlorpyrifos plus sulprofos, respectively. Hence, only the combinations of cypermethrin with methyl parathion and cypermethrin with thiodicarb showed synergism (cotoxicity coefficient $\geq 2.0$ ) and seem to be promising for control of pyrethroid-resistant third-instar tobacco budworms. High-level synergism was observed previously when the combination methyl parathion/permethrin (10:1) was tested with tobacco budworm larvae from an apparently susceptible population (All et al. 1977). A cotoxicity coefficient of 17.5 was calculated for this combination and its good performance against tobacco budworms was confirmed by a field test.

Chlordimetorm was almost nontoxic to the insects tested. The $\mathrm{LC}_{\overline{2} 0}$ 's were 1,068.22 and approximately $1,500 \mu \mathrm{g}$ per vial for susceptible and ICI third instars, respectively. The $\mathrm{LC}_{0,}$ values were 3,642 and approximately $3,800 \mu \mathrm{g}$ per vial for susceptible and ICI strains, respectively. The low chlordimeform toxicity to tobacco budworm larvae agreed with previous studies (Streibert \& Dittrich 1977, Plapp 1979). Piperonyl butoxide alone was also nontoxic to third instars. The $\mathrm{LC}_{50}$ 's were greater than $5,000 \mu \mathrm{g}$ per vial for both tobacco budworm strains.

Chlordimeform synergized cypermethrin and methyl parathion more against the resistant than 
Table 3. Hesistance ratios ${ }^{a}$ cotoxicity coefficients ${ }^{b}$ for combinations and synergisme of insecticides by chlordimeform (CDF), piperonyl butoxide (PA), or both againgt susccpible (S) and resistent (R) third-instar lobscco budworms

\begin{tabular}{|c|c|c|c|}
\hline \multirow[b]{3}{*}{ Insecticides + synergist } & \multirow{3}{*}{$\begin{array}{c}\text { Stone- } \\
\text { ville }(S) \\
\text { Syner- } \\
\text { gism } \\
\text { or co- } \\
\text { toxicity } \\
\text { coeffi- } \\
\text { cient }\end{array}$} & \multirow{2}{*}{\multicolumn{2}{|c|}{ ICI $(\mathrm{R})$}} \\
\hline & & & \\
\hline & & $\begin{array}{l}\text { Syner- } \\
\text { gism or } \\
\text { cotoxicity } \\
\text { coefficient }\end{array}$ & $\begin{array}{l}\text { Resis- } \\
\text { tance } \\
\text { ratio }\end{array}$ \\
\hline Cyperroethrin & - & - & 998 \\
\hline Cypermethrin + CDF & 5.2 & 76.9 & 67.0 \\
\hline Cypermethrin + PB & 2.4 & 158.9 & 15.3 \\
\hline Cypermethrin + CDF + PB & 4.8 & 258.5 & 18.4 \\
\hline Methyl parathion & - & - & 18.9 \\
\hline Methyl parathion + CDF & 3.4 & 81.7 & 0.8 \\
\hline Methyl parathion + $\mathrm{PB}$ & 0.4 & 4.9 & 1.5 \\
\hline Methyl parathion + $\mathrm{CDF}+\mathrm{PB}$ & - & 63.1 & - \\
\hline Chiorpyrifos & - & - & 2.9 \\
\hline Chlorpyrifos + CDF & 1.0 & 1.9 & 1.5 \\
\hline Chlorpyrifos + $\mathrm{PB}$. & 0.2 & - & - \\
\hline Profenofos & - & - & 0.9 \\
\hline Profenofos + CDF & 1.3 & 0.8 & 1.5 \\
\hline Profenofos + PB & - & 0.4 & - \\
\hline Sulprofos & - & - & 1.5 \\
\hline Sulprofos + CDF & 1.1 & 1.1 & 1.5 \\
\hline Sulprofos $+\mathrm{PB}$ & - & 0.4 & - \\
\hline Acephate & - & - & 1.5 \\
\hline Acepbate + CDF & 4.3 & 4,4 & 1.5 \\
\hline Acephate $+\mathrm{PB}$ & - & 1.2 & - \\
\hline Acephate + $\mathrm{CDF}+\mathrm{PB}$ & - & 4.6 & - \\
\hline Methomyl & - & - & 4.3 \\
\hline Methomyl + CDF & 1.0 & 3.3 & 1.3 \\
\hline Methomyl + PB & - & 2.1 & - \\
\hline Methornyl + CDF + PB & - & 1.8 & - \\
\hline Thiodicarb & - & - & 3.9 \\
\hline Thiodicarb + CDF & 4.8 & 5.8 & 3.2 \\
\hline Thiodicarb + PB & - & 1.5 & - \\
\hline Thiodicarb + CDF + PB & - & 6.2 & - \\
\hline Endosulfan & - & - & 1.4 \\
\hline Endosulfan + CDF & 5.3 & 2.9 & 2.6 \\
\hline Chlorpyrifos + sulprofos & $1.5^{b}$ & $1 . A^{b}$ & 1.4 \\
\hline Cypermethrin + thiodicarb & $1.9 b$ & $2.0^{6}$ & 1.2. I \\
\hline \multicolumn{4}{|l|}{ Cypermethrin + thiodicarb } \\
\hline$+\mathrm{CDF}$ & 1.8 & 2.7 & 8.3 \\
\hline Cypermethrin + methyl parathion & - & $41.2^{b}$ & - \\
\hline \multicolumn{4}{|l|}{ Cypermethrin + methyl parathion } \\
\hline$+\mathrm{COF}$ & - & 1.6 & - \\
\hline \multicolumn{4}{|l|}{ Cypermethrin + metbyl parathion } \\
\hline $\begin{array}{l}+\mathrm{PB} \\
\text { Cypermethrin }+ \text { sulprofos }\end{array}$ & - & $0.7^{b}$ & - \\
\hline
\end{tabular}

${ }^{a}$ Calculated by dividing the $\mathrm{LC}_{50}$ for the insecticide or insecticide combination with and witbout synergists against the resistant strain by the corresponding $\mathrm{LC}_{50}$ for the insecticide or insecticide combination with and withoul synergists against the susceptible strain.

${ }^{b}$ Calculated according to Sun \& Johnson (1960). Values $>2$ indicate significant synergism.

c Calculated by dividing the $\mathrm{LC}_{50}$ for the insecticide (or insec (icide combination) by the $L_{50}$ for the insecticide (or insecticide combination) + $\mathrm{CDF}$ with and without $\mathrm{PB}$.

against the susceptible tobacco budworm strain (Table 3). For ICI larvae, synergism levels for both insecticides were about 80 -fold. For other insecticides, synergism by chlordimeform was low ( 5 fold). For the susceptible strain, insecticide synergism at the $\mathrm{LC}_{50}$ level was always low ( $\leq 5$-fold)
Insecticide synergism by chlordimeform was variable for first and third instars. For the susceptible strain, synergism at $\mathrm{LC}_{30}$ was always higher for neonates (Campanhola \& Plapp 1989b) than for third instars. For the ICI strain, synergism by chlordimeform of profenofos, sulprofos, chlorpyrifos, and endosulfan was greater against neonates than against third instars (Campanhola \& Plapp $1988,1989 \mathrm{~b}$ ). However, a synergism of cypermethrin, methyl parathion, acephate, and thiodicarb was higher against third instars.

Piperonyl butoxide produced low synergism or antagonism with insecticides for the susceptible strain (Table 3). The synergism level was 2,4 for cypermethrin, but only 0.4 and 0.2 for methyl parathion and chlorpyrifos, respectively. Thus, antagonism was present for the latter insecticides. Conversely, a very high level of synergism by piperonyl butoxide (158.9-fold) was observed with cypermethrin for the ICI strain. This suggests oxidative detoxification, i.e., metabolic resistance, is present in the ICI strain.

Pyrethroid synergism by piperonyl butoxide has been observed with other insect species. Piperonyl butoxide synergized pyrethroids to different degrees in both susceptible and resistant strains of diamondback moth, Plutella xylostella (L.) (Liu et al. 1984). Pretreatment of a resistant strain of diamondback moth larvae with piperonyl butoxide increased the effectiveness of fenvalerate by 15 fold, deltamethrin 13-fold, permethrin 6-fold, and cypermethrin 3-fold. In a study with first and fourth instar Tribolium castaneum (Herbst) larvae, piperonyl butoxide synergized the toxicity of cispermethrin, trans-and cis-cypermethrin, and deltametbrin (Ishaaya et al. 1983). The investigators suggested that oxidases were more important than esterases in pyrethroid detoxification by this species.

We observed some synergism by piperonyl butoxide with methyl parathion for the ICI strain (Table 3). However, almost no synergism was observed with acephate, methomyl, or thiodicarb. Antagonism by piperonyl butoxide was found for profenofos, sulprofos, and the combination of $c y-$ permethrin with methyl parathion. Piperonyl butoxide might have inhibited the activation of profenofos and sulprofos in resistant larvae. Because piperonyl butoxide synergized cypermethrin and methyl parathion, our data indicated mixed function oxidases may be important in metabolic resistance to these insecticides in the tobacco budworm.

Combining chlordimeform and piperonyl butoxide with cypermethrin was more effective than using either synergist alone. An $\mathrm{LC}_{50}$ of $1,287.46$ $\mu \mathrm{g}$ per vial for cypermethrin only was decreased to $4.98 \mu \mathrm{g}$ per vial cypermethrin when chlordimeform plus piperonyl butoxide were combined with that pyrethroid. This level is only about 4 -fold higher than that of cypermethrin only for the susceptible strain. Therefore, this three-way combination has promise for controlling field populations resistant to pyrethroids. Unfortunately, the light 
instability of piperonyl butoxide (Georghiou 1980) may limit its extensive use and chlordimeform will be withdrawn from the market after the 1989 season. For other insecticides such as acephate, methomyl, and thiodicarb, the three-way combination (insecticide plus chlordimeform plus piperonyl butoxide) was approximately as toxic as chlordimeform only combined with the insecticides. Therefore, synergism of those insecticides was not improved when piperonyl butoxide was combined with chlordimeform.

With the addition of synergists the resistance level to cypermethrin was considerably reduced (Table 3). A 998-fold resistance to cypermethrin was reduced to 67.0-15.3-, and 18.4-fold with the addition of chlordimeform, piperonyl butoxide, and chlordimeform plus piperonyl butoxide, respectively. Likewise, the addition of synergists to methyl parathion practically blocked resistance. Resistance ratios for methyl parathion with chlordimeform or piperony] butoxide were 0.8 and 1.5 , respectively.

The low level of resistance to chlorpyrifos (2.9fold) was decreased to 1.5 -fold with the addition of chlordimeform. The resistance ratios were close to 1 for profenofos, sulprofos, and acephate, that is, no resistance was observed to these compounds. Because no cross-resistance was observed to these S-alkyl phosphorothiolates, they constitute good alternative insecticides for the control of large tobacco budworm larvae. The results of our study agree with those of Sparks (1981) who observed only low resistance levels to chlorpyrifos and profenotos in tobacco budworm populations resistant to methyl parathion.

Bull et al. (1987) postulated that optical isomers that exist as racemic mixtures in technical formulations of profenofos and related insecticides may be mutually synergistic. Whereas mixed-function oxidase enzyme treatment highly increased the anticholinesterase activity of the more toxic (-) isomer of profenofos (34-fold), the activity of the less toxic ( + ) isomer was slightly diminished (2fold) (Wing et al. 1983). Therefore, the enhanced activity of mixed-function oxidases in metabolically resistant tobacco budworm may increase the activity of $(-)$ isomers of compounds such as profenofos, sulprofos, and acephate. Thus, this particular characteristic of these organophosphates seems to allow them to overcome metabolic resistance. This mechanism may explain the efficacy of profenofos and sulprofos to the tobacco budworm with metabolic resistance to methyl parathion (Bull et al. 1987). Topical toxicity tests demonstrated that sulprofos was equal in toxicity to third-instar tobacco budworms that were susceptible or resistant (25-fold) to methyl parathion (Bull 1980).

Low tolerance was observed to the carbamate methomyl, but the addition of chlordimeform practically overcame this tolerance. Some tolerance to another carbamate, thiodicarb, also was observed. However, in this case, chlordimeform seemed not to block the tolerance to this toxicant. These results differed from Sparks's (1981) finding that tobacco budworm larvae resistant to methyl parathion were also resistant to methomyl.

We observed no resistance to endosulfan. The resistance ratio for this insecticide was 1.4 . Combination with chlordimeform tended to enhance the resistance level to endosulfan slightly (2.6-fold). Thus, endosulfan also seems to be a good alternative insecticide for controlling tobacco budworms resistant to pyrethroids.

The combination cypermethrin plus thiodicarb did not block resistance (Table 3). With chlordimeform there was a decrease in the resistance level, but still some resistance was observed (7.5fold). Conversely, no resistance to chlorpyrifos plus sulprofos was present. We do not have a resistance ratio for the combination cypermethrin plus methyl parathion, because we did not test this combi. nation with susceptible third instars.

Io summary, many alternative insecticides or insecticide combinations were effective for controlling large tobacco budworm larvae resistant to pyrethroids. These include cypermethrin plus chlordimeform and piperonyl butoxide, cypermethrin plus methyl parathion, cypermethrin plus thiodicarb plus chlordimeform, the S-alkyl phosphorothiolates profenofos, sulprofos, and acephate (acephate can be combined with chlordimeform), the cyclodiene endosulfan (with or without chlor dimeform), and possibly the oxime carbamates methomyl and thiodicarb, with or without chlordimeform. Chlordimeform was usually a better synergist than piperonyl butoxide for the insecticides studied. In cases in which the combination of insecticide with chlordimeform did not block resistance, the $\mathrm{LC}_{50}$ for the resistant strain became nearly equal to or lower than the $\mathrm{LC}_{50}$ for the insecticide only for the susceptible strain. Besides target site resistance (Campanhola \& Plapp 1988 $1989 b$ ), metabolic resistance (due mostly to enhanced activity of the mixed function oxidases) seems also to be present in the tobacco budworm.

The announcement of the forthcoming suspension of chlordimeform use was received after this study had been completed. However, other formamidines may substitute for chlordimeform as insecticide synergists. An example is amitraz, which was proven to be a good synergist of cypermethrin against pyrethroid-resistant neonate tobacco budworms (Bagwell \& Plapp 1988).

The expression of resistance was variable for different developmental stages of the tobacco budworm. Results obtained here and the ones reported by Campanhola \& Plapp (1989b) for neonate larvae and adults showed that the resistance ratios at the $\mathrm{LC}_{50}$ for cypermethrin tested with the ICI strain were 10.9-, 998-, and 6.3-fold for neonate larvae, third instars, and adult males, respectively. For methyl parathion, the resistance ratios were 1.8 , 18.9 , and 5.2 for neonate larvae, third instars, and adult males, respectively. Thus, the higher levels 
of resistance to cypermethrin and methyl parathion observed in third instars compared with neonate larvae or adults indicate the presence of metabolic resistance in the ICI strain. The presence of resistance to cypermethrin and the absence of resistance to metbyl parathion in ICI neonate larvae suggest the expression of target site $(k d r)$ resistance to pyrethroids (Campanhola \& Plapp 1989b). Therefore, we conclude that target site resistance is a common mechanism of resistance for all life stages of the tobacco budworm, while metabolic resistance is manifested mostly in large larvae.

\section{Acknowledgment}

We thank Don L. Bull for reviewing this manuscript and Robert Blenk, ICl Americas, for supplying samples of the $\mathrm{ICl}$ strain. This manuscript was approved for publication as 24051, Texas Agricultural Experiment Station, College Station, and is a portion of the dissertation of C.C.

\section{Heferences Cited}

Abbott, W. S. 1925. A method of computing the effectiveness of an insecticide. J. Econ. Entomol. 18: 265-267.

All, J. N., M: Ali, E. P. Hornyak \& J. B. Weaver. 1977. Joint action of two pyrethrolds with methyl parathion, methomyl, and chlorpyrifos on Heliothis zea and $H$. virescens in the Laboratory and in cotton and sweet corn. J. Econ. Entomol. 70: 813-817.

Anonymous. 1986. Cotton entomologists seek to delay pyrethroid resistance in insects, p. 8. Mississippi Agriculture \& Forestry Experiment Station Highlights 49.

Aagwell, R. D. \& F. W. Plapp, Jr. 1988. Amitraz: pyrethroid synergism and toxicity to eggs and larvae of the tobacco budworm, pp. 344-346. In Proceedings, Beltwide cotton production research conferences, New Orleans. National Cotton Council of America, Memphis, Tenn.

Bull, D. L. 1980. Fate and efficacy of sulprofos against certain unsects associated with cotton. J. Econ. Entomol. 73: 262

Bull, D. L., I. W. Plapp, Jr., \& T. C. Sparks. 1987. Chemistry and mode of action of insecticides used to control Heliothis spp. on field and horticultural crops. pp. 37-54. In J. C. Schneider et al. [eds.], Theory and tactics of Heliothis population management. Southern Cooperative Series Bulletin 329, Oklahoma State University, Stillwater.

Campanhola, C. \& F. W. Plapp, Jr. 1988. Tobacco budworm resistance to pyrethroids: resistance spectra, synergists, and substilute insecticides, pp. 349352. In Proceedings, Beltwide cotton production research conferences, New Orleans. National Cotton Council of America, Memphis, Tenn.

1989a. Pyrethroid resistance in the tobacco budworm (Lepidoptera: Noctuidae): insecticide bioassays and field monitoring. J. Ecov. Entomol. 82: 22-28.

$1989 \mathrm{~b}$. Toxicity and synergism of insecticides against susceptible and pyrethroid-resislant neonate larvae and adults of the tobacco budworm (Lepidoptera: Noctuidae). J. Econ. Entomol. 82(6); 1527-1533.
Frisbie, R. E. \& W. Plapp, Jr. 1987. Managing insecticide resistant tobacco budworn in Texas cotton. Texas Agriculture Extension Service, College Sta. tion, 500-5-87

Georghiou, G. P. 1980. Insecticide resistance and prospects for its management. Res. Rev. 76: 131-145.

Harding, J. A., F. R. Hufrman, D. A. Wolfenberger \& J.W. Davis. 1972. Insecticidal activity of alphacyano-3-phenoxybenzyl pyrethroids against the boll weevil and tobacco budworm. Southwest. Entomol. 2: $42-45$.

Ishaya, 1., A. Elsner, K. R. S. Ascher \& J. E. Casida. 1983. Synthetic pyrethroids: toxicity and synergism on dietary exposure of Tribolum castaneum (Herbst) larvae. Pestic. Soi. 14: $367-372$.

Leonard, B. R., J. B. Graves, T. C. Sparks \& A. M. Pavloff. 1987. Susceptibility of bollworm and tobacco budworm larvae to pyrethroid and organophosphate insecticides, pp. 320-324. In Proceedings, Beltwide cotton production researcb conferences, Dallas. National Cotton Council of America, Memphis, Tenn.

Liu, M. Y., J. S. Chen \& C. N. Sun. 1984. Synergism of pyrethroids by several compounds in larvae of the diamondback moth (Lepidoptera: Plutellidae. ). Econ. Entomol. 77: 851-856.

Lutrell, R. G. \& R. T. Roush. 1987. Strategic approaches to avoid or delay development of resistance to insecticides, pp. 31-33. In Proceedings, Beltwide cotton production research conlerences, Dallas. National Cotton Council of America, Memphis, Tenn.

Marinez-Carrillo, J.L. \& H. T. Reynolds. 1983. Dosage-mortality studies with pyrethroids and otber insecticides on the tobacco budworm (Lepidoptera: Noctuidae) from the Imperial Valley, California. I. Econ. Entomol. 76: 983-986.

Muehleisen, D. P. 1987. Induction and regulation of deloxification enzymes in Helolhis zea (Boddie) by plant allelochemicals and insecticides. Ph. D. dissertation, Texas A\&M University, College Station.

Plapp, F. W., Jr. 1979. Synergism of pyrethroid insecticides by formamidines against Heliothis pests of cotton. J. Econ. Entomol 72: 667-670.

1981. Toxicity of syntbetic pyrethroids to laboratory and field populations of the tobacco budworm in Central Texis. J. Econ. Entomol. 74: 207-209.

Plapp, F. W., Jr., G. M. MeWhorter \& W. H. Vance. 1987. Monitoring for pyrethroid resistance in the tobacco budworm in Texas-1986, pp. 324-326. In Proceedings, Beltwide cotton production research conferences, Dallas. National Cotton Council of Amenica, Memphis, Tenn.

Plapp,F,W., Jr., R.E. Frisbie \& J.A. Jackman, 1988. Monitoring for pyrethroid resistance in the tobacco budworm-1987, pp. 237-239. In Proceedings, Beltwide cotton production research conferences, New Orleans, National Cotton Council of America, Memphis, Tenn.

Plapp, F. W., Jr., R. E. Frishie \& J. A. Jackman. In press. Monitoring for pyrethroid resistance in $\mathrm{He}$ liothis spp. in Texas in 1988. In Proceedings, Beltwide cotton production research conferences, Nasbville, Tenn. National Cotton Council of America, Memphis, Tenn.

SAS Instinte. 1982. SAS user's guide: statistics. SAS Institute, Cary, N.C.

Sparks, T. C. 1981. Development of insecticide resistance in Heliothis zea and $H$. virescens in North America. Bull. Entomol. Soc. Arn. 27: 186-192. 
Staetz, C. E. 1985. Susceptibility of Heliothis vires. cens (F.) (Lepidoptera: Noctuidae) to permethrin from across the colton belt: a five year study. J. Econ. Entomol. 78: 505-510.

Sireibert, H. B. \& V. Dittrich. 1977. Toxicological response of insect eggs and larvae to a saturated atmosphere of chlordimeform. J. Econ. Entornol. 70: $57-59$.

Sun, Y. P. \& E. R. Johnson. 1960. Analysis of joint action of insecticides against housellies. J. Econ. Entomol. 53: 887-892.

Wing, K. D., A. H. Glickman \& J. E. Casida. 1983. Oxidative bionctivation of $\mathrm{S}$-alkyl phosphorothiolate pesticides: slereospecificity of profenofos insecticide activation. Science 219:63.

Received for publicalion 12 October 1988; accepled 3) March 1989. 